\title{
LA VERDAD, CONSTRUCTO HUMANO EN LA CONTINGENCIA DEL LENGUAJE: UN PLANTEAMIENTO DESDE RICHARD RORTY
}

\section{The Truth, Human Constructo in the Contingency of the Language: A Position from Richard Rorty}

\author{
Diana Marcela Pinto P* . \\ Recibido: 25 de marzo de 2008 • Revisado: 14 de mayo de 2007 - Aceptado: 30 de mayo de 2008
}

\begin{abstract}
Un tratado filosófico que expone un sistema está condenado a contener pasajes flojos; no porque le falte talento al filósofo, sino porque así lo exige la forma de un tratado; ya que, antes de llegar a sus conclusiones innovadoras, el filósofo se ve obligado a explicar lo que los demás dicen del problema, obligado a refutarles, a proponer otras soluciones, elegir la mejor, alegar a su favor, el argumento que sorprende codeándose con el que se da por supuesto, etc., de tal manera que al lector le entran ganas de saltar páginas para llegar por fin al meollo de la cuestión, al pensamiento original del filósofo.
\end{abstract}

Milán Kundera Los testamentos traicionados

\section{Resumen}

La filosofía del lenguaje surge como la posibilitadora de la búsqueda de la verdad, función que ha acompañado siempre a la filosofía desde su aparición en Grecia. Con el lenguaje como protagonista, recordamos que la verdad ha estado ligada a aquel gracias a la herencia occidental de nuestro pensamiento. En este contexto, Richard Rorty nos plantea que la verdad tan solo está en las proposiciones, fruto de lenguajes elaborados por los hombres. Esta visión se opone a conceptos filosóficos como el esencialismo y el representacionalismo, y a creencias como la labor sacerdotal del filósofo, entre otras cosas. Pero la consecuencia más dura del pensamiento de nuestro autor

Profesional en Estudios en Filosofía de la Universidad El Minuto de Dios. En la actualidad desarrolla una investigación sobre filosofía del lenguaje desde Frege, Davidson y Rorty en la que analiza el problema de la verdad. 
es la consideración de la filosofía como un género literario más, en el cual la metaforicidad ha estado presente en sus discursos a pesar de su pretensión de objetividad y de erigirse como la develadora de la verdad.

\title{
Palabras clave
}

Lenguaje, verdad, contingencia, literal, metáfora, filosofía, género literario.

\begin{abstract}
The philosophy of the language arises as the one that makes possible the search of the truth, function that has always accompanied the philosophy from its appearance in Greece. With the language as the main character, we remember that the truth has been bound to it thanks to the western inheritance of our thought. In this context, Richard Rorty outlines us that the truth is only found in the propositions, fruit of languages elaborated by human beings. This vision opposes itself to philosophical concepts like the essentialism and the representational, and to beliefs like the philosopher's priestly work, among other things. But the hardest consequence of our author's thought is the recognition of the philosophy like a literary gender, where the metaphorical has been present in his speeches in spite of his desire for objectivity and of being erected as the one to unveil the truth.
\end{abstract}

\section{Key words}

Language, truth, contingency, literal, metaphor, philosophy, literary gender.

\section{Introducción}

Como sabemos, a principios del siglo XX el lenguaje toma un papel protagónico en el campo de la filosofía, ya que se empieza a observar una fuerte identificación entre los problemas del lenguaje y los filosóficos. En este ambiente surge la filosofía del lenguaje "como un nuevo paradigma, que sustituye el concepto central del paradigma anterior (la conciencia), por un elemento revolucionario que funda un paradigma autónomo: el lenguaje" (Rodríguez, 2002, p. 15).

Con éste como protagonista, la filosofía del lenguaje se explicita bajo la forma de análisis filosófico, hermenéutica, estructuralismo, entre otros. "Así las cosas, el análisis filosófico es susceptible de ser entendido como un capítulo muy importante dentro de la filosofía del lenguaje, que da cuenta del fenómeno rotulado por Rorty como giro lingüístico" (Rodríguez, 2002, p. 15).
Debemos nombrar al filósofo alemán Gottob Frege como precursor de este cambio en la filosofía, pues como nos dice Dummet: "Ia filosofía analítica es simplemente la filosofía posterior a Frege" (Acero, p. 20). Ahora bien, por tradición, el filósofo se siente en la obligación y el derecho de buscar la verdad y Frege no podía ser la excepción, pues para él la verdad señalaba la dirección de la lógica: "a la lógica le toca decretar las leyes del ser verdad" (Frege, 1995, p. 49).

Entonces el lenguaje y la verdad se enlazan, ya que aquél es el camino, el medio, para llegar a ésta. Por ello, la filosofía del lenguaje se preocupa de esclarecer de qué se habla cuando se habla; siguiendo con Frege, los signos designan un objeto, tienen una referencia, $y$ ella es importante, pues nos interesa el valor veritativo de los enunciados. Hay una correspondencia entre el lenguaje y los objetos designados que permiten dar un valor de verdad. Pero este filósofo es solo el iniciador de toda una serie de planteamientos que se harán en torno a este tema. 
Como vemos, la filosofía intenta encontrar la verdad por medio del análisis del lenguaje. En este contexto se halla el filósofo norteamericano Richard Rorty, quien plantea que "solo las proposiciones pueden ser verdaderas, y los seres humanos hacen las verdades al hacer los lenguajes en los cuales formulan las proposiciones" (Rorty, 2001, p. 36).

Por lo anterior, el presente trabajo se centrará en el tema de la verdad, la cual fue buscada desde la aparición de la filosofía y que está ligada desde ese entonces con el lenguaje. Pretendemos presentar que la verdad no debe ser entendida actualmente como el descubrimiento de una realidad intrínseca, sino como un constructo humano que al ser elaborado por un lenguaje, es por tanto contingente. Para llevar a cabo nuestro propósito nos centramos en el pensamiento de Rorty, acudiendo en algunas ocasiones a Donald Davidson, base de muchos planteamientos hechos por nuestro autor; con lo cual no pretendemos desconocer diversos autores, corrientes, o conceptos filosóficos, que han contribuido a lo largo de la historia al debate sobre estos temas.

Por otro lado, hemos dividido el texto en cinco secciones. Empezaremos haciendo una pequeña alusión a la influencia griega en nuestro pensamiento occidental, con las figuras de Parménides y Platón, quienes nos llevaron por el camino de la búsqueda de la verdad. Así, podremos recordar cómo ésta se liga al lenguaje desde aquella época.

En segundo lugar presentaremos el paso de la noción de verdad como descubrimiento de naturalezas intrínsecas, tradicional del pensamiento filosófico, a la de una verdad construida en el lenguaje. Proseguiremos con una exposición del proceso de ruptura del representacionalismo, que según nuestro autor, nos permite pasar de la consideración del lenguaje como medio al de herramienta.

Como cuarto punto veremos cómo la búsqueda de la verdad nos lleva a que se imponga la cultura literaria, la cual permite que se expanda la imaginación, y usa un lenguaje metafórico. Para terminar, abordaremos las implicaciones que el cambio de concepciones de lenguaje y verdad trae, llevándonos hasta el punto de poner a la filosofía como un género literario más.

\section{La influencia parmenídea en el pensamiento occidental los orígenes griegos del pensamiento occidental}

En la Grecia antigua la búsqueda por el principio de la realidad, (arjé), lleva a Parménides a establecer dos vías que conducen al conocimiento, separando así la opinión (doxa), de la verdad (alétheia), y con ello, el mito del logos. Entonces, desde allí queda establecido que el mito pertenece al ámbito de la opinión, en el que no se da el conocimiento verdadero. Aunque el poeta había ofrecido su versión de mundo, ésta encara la realidad desde la metáfora, lo cual pertenece al campo de la opinión al no ser literal y, por tanto, no lleva a la verdad. Por el contrario, el logos se erige como el lugar donde reside la verdad, la cual se hace palabra, por ello, Parménides formuló que lo que no se puede pensar ni decir no es. Desde ese entonces, lenguaje y verdad van de la mano, y están en el campo de la filosofía:

\footnotetext{
No es para nada gratuito que el origen de la escritura y la filosofía tengan un desarrollo paralelo en el mundo griego. La escritura, grámmata, permitía fijar el desocultamiento, alétheia, es decir, lo que hay de verdadero en el mundo. La filosofía surge entonces como correlativa a la verdad que puede ser buscada, encontrada, puesta a prueba en el ágora a través de la oralidad y luego fijada en la escritura. El conocimiento filosófico se erigió como la forma más acertada de decir algo sobre la naturaleza, así Ios poetas hubiesen dicho algo sobre ella (Fonseca, 2007, p. 15).
}

Posteriormente, Platón toma el pensamiento parmenídeo y considera que la filosofía lleva a los hombres por el camino de la verdad. El ser verdadero (la realidad) se encuentra en el mundo de las ideas, en lo inteligible, pues lo inmediato (lo fáctico) es un mundo de sombras y de apariencia. Por ello, el hombre va en busca de la realidad para poder contemplar la verdad. 
Ahora bien, "el lenguaje constituye la dialéctica y ésta a su vez es el camino para la captación de la verdad" (Fonseca, 2007, p. 21). Además, como nos dice Platón en su obra Sofista: los nombres designan las cosas y el mejor hacedor de nombres es el filósofo, pues es quien mejor conoce la realidad (Fonseca, 2007, p. 21).

Como vemos, los planteamientos parmenídeos nos permitieron comenzar a transitar la ruta hacia la búsqueda de la verdad fuertemente anclada en el lenguaje, marcando definitivamente nuestro pensamiento'. Sin embargo, Rorty nos ofrece algunas interpretaciones que desestabilizan esta tradición y hacen tambalear muchas de nuestras creencias más ortodoxas.

\section{Lenguaje y verdad constructos humanos}

Rorty nos plantea que desde la Revolución Francesa se empezó a dar un cambio en la manera de pensar de los hombres, con respecto a la verdad; se consideró que no era necesario hallarla sino que podía ser construida. Por un lado, los utopistas políticos abandonaban la noción de voluntad de Dios o de naturaleza humana, para erigir una nueva sociedad. Al mismo tiempo, los artistas se dieron cuenta de que no era necesario imitar la naturaleza, pues poseían una labor creadora.

Por este motivo se dan dos tendencias en la filosofía, por un lado, los que se mantienen fieles a la ilustración y consideran que la verdad es algo que se descubre, en la que hay una realidad fuera de lo humano que debe ser hallada. Esta posición defiende el riguroso hecho científico, objetivo, en contraposición de lo subjetivo, o lo metafórico como la expresión: "hacer la verdad".

$1 \quad$ Rorty plantea al respecto de la influencia de Parménides: "Si no fuera por nuestra necesidad parmenídea de hallarnos bajo el mandato de la verdad, de sentirnos obligados por las cosas a llamarlas por sus nombres propios, jamás habríamos pensado que una disciplina denominada 'teoría del conocimiento' pudiera ilustrarnos de la 'objetividad', ni que otra denominada 'filosofía del lenguaje' pudiera decirnos cómo se engarzan las palabras en el mundo" (Rorty, 1996, p. 211).
Por otro lado, están los filósofos que consideran que la verdad se construye, quienes se adhieren al grupo de los utopistas políticos y los artistas innovadores, quienes consideran que la ciencia no da ninguna lección moral. La filosofía vista desde esta segunda perspectiva lleva dos siglos de existencia y se dio gracias a los filósofos idealistas, quienes consideraban que la verdad no está afuera en el mundo, sino en el propio hombre que la elabora.

Sin embargo, los idealistas en su rebeldía por separarse de la idea de que la verdad está afuera en espera de ser descubierta, la pusieron el en interior del hombre que debía construirla, pero cometieron un error al considerar que la mente era una cosa que poseía naturaleza intrínseca, entonces volvieron al mismo punto de partida en el cual la verdad debía ser descubierta, aunque ahora en el yo.

Además, los idealistas al llevar la verdad al yo, que por su condición de verdad está ligada a lo real, anulan la existencia del mundo espacio-temporal como algo externo y lo ligan a la mente humana, poniéndola como su causa. Esta consecuencia es fruto de confundir la idea de que el mundo está afuera, con la verdad está afuera. Decir que el mundo está afuera significa que él no es creación humana y que las cosas espaciotemporales tienen sus propias causas, diferentes a los estados mentales humanos.

Ahora bien, lo anterior, así como lo expuesto arriba, que la filosofía desde su nacimiento en Grecia liga verdad con lenguaje, nos lleva a afirmar que "decir que la verdad no está ahí afuera es simplemente decir que donde no hay proposiciones no hay verdad, que las proposiciones son elementos de los lenguajes humanos y que los lenguajes humanos son creaciones humanas" ( Rorty, 2001, p. 25).

Por tanto, no hay que confundir, como lo hacen los idealistas, que existe un mundo ahí afuera que tiene sus propias causas con que la verdad está en el mundo, pues la verdad no puede existir fuera de la mente de los hombres y es elaborada en el lenguaje. 
Sin embargo, también debemos considerar que las dos tendencias mencionadas antes, los filósofos que buscan la verdad en el mundo, en el que ponen una naturaleza intrínseca que descubrir, así como los idealistas, que ponen la verdad en la mente de los hombres, pero que no abandonan la idea de la naturaleza intrínseca a la que llegar -y que según Rorty están en el mismo grupo con los poetas-, no ofrecen una descripción exacta del mundo, o de la realidad.

Como lo afirma nuestro autor:

[...] de acuerdo con esta forma de ver, los grandes científicos inventan descripciones del mundo que son útiles para predecir y controlar los acontecimientos, igual que los poetas y los pensadores políticos inventan otras descripciones del mundo con vistas a otros fines (Rorty, 2001, p. 24).

Pero el punto importante es que el mundo no habla, sólo los hombres lo hacen, por ello, la verdad no se puede buscar fuera del lenguaje humano:

La verdad no puede estar ahí afuera - no puede existir independientemente de la mente humana - porque las proposiciones no pueden tener esa existencia, estar ahí afuera. El mundo está ahí afuera, pero las descripciones del mundo no. Sólo las descripciones del mundo pueden ser verdaderas o falsas. El mundo de por sí - sin el auxilio de las actividades descriptivas de los seres humanos- no puede serlo (Rorty, 2001, p. 25).

Por tanto, según nuestro autor, no debemos pretender que haya una correspondencia exacta entre la realidad y las descripciones hechas en el lenguaje, pues ya no se trata de descubrir esencias para llegar a la verdad en un sentido absoluto como se solía creer, sea en el mundo o en el yo, sino de elaborar lenguajes. Estos lenguajes no buscan adecuarse a una realidad, sino a la descripción que pretende hacerse de ésta.

\section{La ruptura del representacionalismo y la concepción del lenguaje como herramienta}

Para abordar el problema de la no exactitud en la correspondencia entre la realidad y el lenguaje que enunciamos antes, el mismo Rorty acude al filósofo norteamericano Donald Davidson, pues considera que éste "rompe con la noción del lenguaje como algo que puede mantener una relación de adecuación o de inadecuación con el mundo o con el yo" (Rorty, 2001 p. 30). Además:

El tratamiento que Davidson hace de la verdad se enlaza con su tratamiento del aprendizaje del lenguaje y de la metáfora, para formar el primer tratamiento sistemático del lenguaje que rompe completamente con la noción de lenguaje como algo que puede mantener una relación de adecuación o inadecuación con el mundo o con el yo. Porque Davidson rompe con la noción de que el lenguaje es un medio: un medio de representación o de expresión (p. 30).

Este filósofo se aparta de la concepción de correspondencia entre el lenguaje y el mundo, al abandonar la idea de que el lenguaje es un medio para la representación de la realidad, en la cual sujeto y objeto establecen una red de interacción. Concebir el lenguaje como medio requiere que los deseos y las creencias estén en correspondencia entre el yo y la realidad, por el contrario, si no se da una red de interacción entre estos elementos, las creencias son susceptibles de crítica al no corresponder a una realidad y los deseos son considerados irracionales o innaturales al no corresponder con la naturaleza del yo humano.

El idealismo ya había querido acabar con el dualismo sujeto-objeto, pero no pudo hacerlo; asimismo, se pretendió que a partir de la sustitución de la categoría de mente o conciencia, por la de lenguaje, se lograría un avance, al abandonar las explicaciones metafísicas 
por las causales. Sin embargo, con esta noción se continuó haciendo la relación sujeto-objeto, aunque con la mediación del lenguaje.

Davidson nos libera de ese proceso pendular, al abandonar la idea de que el lenguaje es un medio para la representación, en cual el yo o el mundo poseen una naturaleza intrínseca esperando ser conocida. Propone en cambio que el lenguaje sea considerado una herramienta. Veamos lo que dice Rorty al respecto de esta visión:

La analogía adecuada es la de la invención de nuevas herramientas destinadas a ocupar el lugar de las viejas. El alcanzar un léxico así se asemeja más al hecho de abandonar la palanca y la cuña porque se ha concebido la polea, o de excluir el yeso mate y la témpera porque se ha encontrado la forma de proporcionar apropiadamente el lienzo (Rorty, p. 32).

La nueva noción de lenguaje lo considera como "una señal que indica que es deseable emplear cierto léxico cuando se intenta hacer frente a ciertas especies de organismos" (Rorty, 2001 p. 34). Con ello, se coloca al lenguaje como algo natural al convertir todas las cuestiones acerca de éste con el resto del universo en cuestiones causales. Asimismo, ya no es importante hacerse preguntas como ¿cuál es la relación entre el lenguaje y el pensamiento?, sino iobstaculiza el uso de estas palabras el uso que hacemos de aquellas otras?

Al considerar el lenguaje de esta forma, lo relevante no es preguntarse si las creencias que se tienen son contradictorias, si corresponden o no a una realidad, sino si se está haciendo un uso adecuado del lenguaje. Por ello, los léxicos cambian según las necesidades que se tengan en un determinado momento, la elaboración de nuevos léxicos no consiste en la correspondencia del lenguaje con una realidad descubierta, sino en la mejor manera de expresar lo que se quiere decir.

Ahora bien, según Davidson al dejar el dualismo sujeto-objeto atrás no se renuncia a hallar una verdad, por el contrario:
Dado el dogma de un dualismo de esquema y realidad, conseguimos una relatividad conceptual y una verdad relativa a un esquema. Sin el dogma, esta forma de relatividad se va al traste. Como es natural, la verdad de las oraciones sigue siendo relativa al lenguaje, pero esto es algo perfectamente objetivo. Al abandonar el dualismo de esquema y mundo, no renunciamos al mundo, sino que restablecemos el contacto no mediado con los objetos conocidos cuyas travesuras hacen que nuestras oraciones $y$ opiniones sean verdaderas o falsas (Rorty, 2001b, p. 283).

En este punto, podemos notar claramente porque afirmábamos que la verdad no debe ser entendida como el descubrimiento de una naturaleza intrínseca, sino como un constructo humano que al ser elaborado por un lenguaje, es por tanto contingente. Por eso, lo que consideramos verdadero varía de un momento histórico a otro. Sin embargo, para ampliar la visión de lo que significa esta afirmación, veremos a continuación como la verdad ha sido buscada por los hombres para hallar la redención.

\section{Cultura literaria: el nuevo camino hacia la verdad redentora}

Al tomar la verdad como una entidad inmutable $y$ eterna que se debe alcanzar, los hombres emprenden un camino de búsqueda para lograr la redención por medio de ella, para poder responder a la pregunta: ¿qué hacer con la existencia? Ahora bien, según Rorty la verdad redentora es "la necesidad de hacer encajar todo -todas las cosas, personas, eventos, ideas y poemas- en un único contexto, un contexto que de algún modo se revelará como natural, destinado y único" (Rorty, 2005 p. 59). Como consecuencia de esta búsqueda, nuestro autor plantea que los intelectuales ${ }^{2}$ de Occidente han tenido la esperanza de redención primero en Dios, luego en la filosofía y ahora en la literatura.
2 Intelectual para Rorty significa el sujeto que investiga y lee libros porque aspira a encontrar la verdad redentora, no el que lee por simple entretenimiento. 
La respuesta sobre qué hacer con la existencia, primero fue buscada en Dios, considerado Suprema Verdad en la religión cristiana monoteísta. Luego del Renacimiento, se desplaza a Dios para darle paso a la razón, considerada la vía eficaz para hallar la verdad objetiva que la religión empañaba. Posteriormente, el cambio que se da de la filosofía a la cultura literaria, ocurre cuando Hegel plantea que el color de la filosofía es grisáceo como cuando una forma de vida envejece (Rorty, 2005, p. 61). Con ello hace que aquel puesto redentor que se reclamaba para la filosofía caiga, ya que "desde la época de Hegel, los intelectuales han ido perdiendo confianza en la filosofía, en la idea de que la redención puede venir en forma de creencias verdaderas" (Rorty, 2005, p. 61).

En consecuencia, la pregunta por la existencia de la verdad cambia por ¿qué hay de nuevo?, cambio que según Rorty:

representa un deseable reemplazo de las malas preguntas como ¿qué es el ser?, ¿qué es lo verdaderamente real? y ¿qué es el hombre?, por la sensible pregunta ¿Alguien tiene una nueva idea acerca de cómo los humanos podemos dirigir por nosotros mismos nuestra existencia? (Rorty, 2205 p. 62).

Es en este momento cuando la cultura literaria toma un lugar preponderante en el cuestionamiento de la existencia humana, pero le da una mirada nueva. Esa nueva visión se encuentra en forma de libros, pinturas, canciones y todas aquellas construcciones, en las que sus autores han plasmado diferentes puntos de la diversidad humana. Entonces, lo que hace rica una cultura es precisamente la diversidad que en ella se encuentre, por lo que ya no hay ningún punto de vista privilegiado; esto contribuye a la tolerancia, al admitir que todas las interpretaciones son válidas.

Por lo anterior, la cultura literaria abandona aquella idea común a la religión y la filosofía que ponia la verdad y, por tanto la redención, en relación con algo que trascendía lo humano. La redención ahora es alcanzada tocando los límites de la imaginación humana, que en forma de metáfora, permite hablar de manera diferente para trascender dichos límites e ir siempre en busca de la novedad.

\section{La filosofía, un género literario más}

Además de haber abandonado la noción de lenguaje como medio y colocarlo como herramienta, Davidson plantea que:

\begin{abstract}
No existe cosa semejante a un lenguaje, al menos en el sentido en que lo han concebido los filósofos. No hay, por tanto, una cosa semejante que pueda ser enseñada o dominada. Debemos renunciar a la idea de que existe una estructura definida poseída en común que los usuarios de un lenguaje dominan y después aplican a situaciones [...] debemos renunciar al intento de aclarar el modo en que nos comuniquemos recurriendo a convenciones (Rorty, 2001, p. 35).
\end{abstract}

Por ello, para lograr que dos personas lleguen a entenderse recíprocamente por medio del habla, todo lo que necesitan es la aptitud de coincidir en teorías momentáneas de una expresión a otra. Esta visión del lenguaje como algo que depende del uso inmediato, lo pone en una relación causal con el mundo, borra esquemas y todo tipo de convencionalismos. Pero si además recordamos que tampoco hay una correspondencia exacta entre la realidad y las descripciones hechas en el lenguaje, podemos darnos cuenta que la literalidad y la metaforicidad son igualmente válidas, ya que sirven para ser utilizadas en léxicos momentáneos.

Aquí cobra sentido que los hombres estén constantemente cambiando un léxico por otro, pues el lenguaje no es algo estático, no es una entidad ni representa esencias; por ello requiere ser renovado según lo que se pretenda decir, según las necesidades de un momento histórico:

Concebir la historia del lenguaje y, por tanto, la de las artes, las ciencias y el sentido moral, como la historia de la metáfora, es excluir la imagen de la mente humana, o de los lenguajes humanos, como cosas que se tornan cada vez más aptas para los 
propósitos a los que Dios o la naturaleza los han destinado; por ejemplo, los de expresar cada vez más significados o de representar cada vez más hechos (Rorty, 2001a, p.36).

Ahora bien, con el auge de la cultura literaria fruto de la caída del representacionalismo y el esencialismo, la imaginación que habla en forma de metáfora, surge como la que hace posible hablar siempre de forma diferente. Pero al mencionar a la metáfora, recordamos que ésta era considerada, según expusimos al principio, como algo inferior, pues no se adaptaba a la realidad, no expresaba la verdad, sin embargo, como vemos, con ella se renuevan los léxicos al explorar nuevos terrenos no transitados anteriormente.

La diferencia entre lo metafórico y lo literal es vista por Davidson no como la distinción entre dos especies de significados, sino como la distinción entre un uso habitual y un uso inhabitual de sonidos y marcas:

Los usos literales de sonidos y marcas son los usos que podemos manejar por medio de las viejas teorías acerca de lo que las personas dirán en determinadas condiciones. Su uso metafórico es el que hace que nos dediquemos a desarrollar una nueva teoría [...] no debemos pensar que las expresiones metafóricas tengan significados distintos de sus significados literales (Rorty, 2001a, pp.36-37).

Entonces, lo literal es sólo lo metafórico utilizado habitualmente, pues unas metáforas van dando paso a otras cuando las anteriores resultan ya obsoletas para hablar de algo. Las metáforas mueren con léxicos que ya no se usan. Es así como lo literal, sería la metáfora usada en sentido habitual y las nuevas metáforas esperan imponerse para volverse literales.

Por ello el filósofo es un poeta, porque es un hacedor de nuevas palabras, inventa nuevas formas de hablar, contribuye a que se hable de manera diferente y se renueven los léxicos. Como nos dice Rorty: "Heidegger desea que consideremos la metafísica como una forma de poesía inauténtica, una poesía que se considera a sí misma como antipoesía, una serie de metáforas cuyos autores las concibieron como evasión de la metaforicidad" (Rorty, 1993, p. 61).

Lo anterior pone a la religión y a la filosofía como géneros literarios, pues no son poseedoras de una facultad que acerque al hombre con una realidad divina, llámese Dios o verdad, sino son fruto de metáforas que se han impuesto a lo largo de la historia. Tomando el caso específico de la filosofía, ésta que se preciaba de ser develadora de la verdad al poseer un discurso objetivo anclado en la realidad, debe reconocer que ya no tiene sentido alguno discutir sobre verdades absolutas. Ni tampoco hay que preocuparse demasiado por definir hasta dónde va la realidad o la ficción, ya que sus fronteras son difusas, pues vivimos en un mundo interpretado, un mundo que muda y acerca del cual realizamos múltiples redescripciones.

Ya es hora de despedirnos de esa idea de filósofo con una función sacerdotal, que nos pone en contacto con un dominio que trasciende lo humano, así como de la creencia de un lenguaje como representación, o como diría Rorty: espejo de la naturaleza. Éstas son pues, algunas implicaciones que se evidencian a partir del pensamiento de Rorty, al considerar que: "Nuestro lenguaje y nuestra cultura no son sino una contingencia" (Rorty, 2001a, p.36).

\section{Referencias}

Acero, J. (1985). Filosofía y análisis del lenguaje. Madrid: Cincel.

Fonseca, Miguel. (2007). Discurso sobre los límites del lenguaje. Bogotá: Universidad Santo Tomás.

Frege, G. (1995). El pensamiento: una investigación lógica. En Luis Valdés. En Búsqueda del significado. Madrid: Tecnos.

Rodríguez, C. (2002). La filosofía analítica en Colombia. Bogotá: El Búho. 
Rorty, R. (1993). Ensayos sobre Heidegger y otros pensadores contemporáneos. Barcelona: Paidós.

Rorty, R. (1996a). Consecuencias del pragmatismo. Madrid: Tecnos.

Rorty, R. (1996b). Objetividad, relativismo y verdad. Barcelona: Paidós.
Rorty, R. (2001c). Contingencia, ironía y solidaridad. Barcelona: Paidós.

Rorty, R. (2001d). La filosofía y el espejo de la naturaleza. Madrid: Cátedra.

Rorty, R. (2005). El ocaso de la verdad redentora y el ascenso de la cultura literaria. Hitos Revista de Filosofía. 